\section{FORMAÇÃO DOCENTE NA LICENCIATURA EM EDUCAÇÃO DO CAMPO DA UNIVERSIDADE DE BRASÍLIA CAMPUS PLANALTINA}

\section{TEACHER TRAINING IN THE DEGREE IN COUNTRYSIDE EDUCATION AT UNIVERSITY OF BRASÍLIA CAMPUS PLANALTINA}

Elinete Pereira dos Santos ${ }^{1} /$ Domingos Rodrigues da Trindade ${ }^{2, *}$

\section{INTRODUÇÃO}

As Licenciaturas em Educação do Campo surgem da luta dos Movimentos Sociais e Sindicais dos povos que vivem no meio rural para assegurar o acesso e a permanência dos camponeses à educação superior na universidade pública. O Programa Nacional de Educação do Campo (PRONACAMPO) é a política pública que dá materialidade à formação de professores para o campo, por meio do Decreto n. $^{\circ} 7.352 / 2010$, cujo objetivo é formar professores, por área do conhecimento, para atuarem nas escolas de Educação Básica do campo, tendo como eixo a gestão de processos educativos escolares e comunitários.

A discussão que perpassa o texto traz como problema de pesquisa a questão de como se dá a formação docente, a organização curricular e pedagógica do curso de Licenciatura em Educação do Campo da UnB/Planaltina, bem como as contribuições dos movimentos sociais à $\mathrm{Li}$ cenciatura.
${ }^{1}$ Universidade Estadual do Sudoeste da Bahia, Vitória da Conquista, Bahia Brasil.

${ }^{2}$ Departamento de Educação Campus XII, Universidade do Estado da Bahia, Guanambi, Bahia - Brasil

"E-mail para correspondência: dtrindade@ uneb.br

\section{RESUMO}

O artigo analisa a formação docente na Licenciatura em Educação do Campo na Universidade de Brasília (UnB), Campos Planaltina-DF, a organização curricular e pedagógica do curso. Como problema, questiona como se dá a formação docente e quais as contribuições dos movimentos sociais para a Licenciatura em Educação do Campo da Universidade de Brasília? A metodologia utilizou referenciais na pesquisa qualitativa, em estudos bibliográficos, análise documental e questionário aplicado a professores. A análise de dados pautou-se nas categorias: organização curricular, organização pedagógica e movimentos sociais do campo. Conclui que a organização curricular da LEdoC está coesa com a proposta do curso; a relação movimentos sociais e licenciatura, no Projeto Político Pedagógico, traz poucos elementos de como essa relação deve ser mediada, e não faz discussão aprofundada da concepção teórica de formação por área.

Palavras-chave: Licenciatura em Educação do Campo. Formação de Professores. Educação do Campo.

\section{ABSTRACT}

The article analyzes the teacher training in the Degree in Countryside Education at the University of Brasília (UnB), Campus Planaltina-DF, the curricular and pedagogical organization of the course. As a problem, it examines: how does the teacher training take place and what are the social movements' contributions to the Countryside Education Degree at the University of Brasília? The methodology used references in qualitative research, in bibliographic studies, documentary analysis and questionnaire applied to teachers. The data analysis was based on the categories: curricular organization, pedagogical organization and social movements of the field. It concludes that, the LEdoC curriculum organization is consistent with the course proposal; the relation social movements and teacher training, in the Political Pedagogical Project, brings few elements of how this relation must be mediated, and does not make in depth discussion of the theoretical conception of formation by area.

Keywords: Degree in Countryside Education. Teacher training. Countryside Education.

Submetido em: 28 de mai. 2018

Aceito em: 06 de nov. 2018 
comCiência

Uma revista multidisciplinar
Formação docente na licenciatura em educação do campo da Universidade de Brasília Campus Planaltina
Para dar sustentação teórica à pesquisa, utilizamos como referencial os estudos de Gramsci (1982; 2002), com a discussão acerca do papel da educação na formação da classe trabalhadora; Caldart (2011); Molina (2011); Sá (2011), com a reflexão sobre a formação de professores nas Licenciaturas em Educação do Campo e a vinculação dessa proposta ao ideal da classe trabalhadora do campo, e Barbosa (2012) com as contribuições acerca do processo de constituição da Licenciatura em Educação do Campo (LEdoC/UnB).

A metodologia respaldou-se na abordagem qualitativa de pesquisa, por meio de estudos bibliográficos, análise documental e de questionário organizado a partir de três categorias de análise, a saber: organização curricular, organização pedagógica e movimentos sociais.

O artigo está estruturado em quatro partes. A primeira apresenta o histórico da Licenciatura em Educação do Campo, desde a proposta do PRONACAMPO até a materialização da licenciatura pesquisada. A segunda, uma discussão sobre a organização curricular da LEdoC/UnB e a proposta de formação por área do conhecimento, a qual compreende a docência multidisciplinar. A terceira reflete acerca da proposta pedagógica da Licenciatura, que se dá por meio da Pedagogia da Alternância e seus diferentes tempos formativos organizados no contexto da Universidade e da Comunidade, ou seja, Tempo Universidade (TU) e Tempo Comunidade (TC). A quarta apresenta a análise dos dados obtidos durante a pesquisa a partir das categorias trabalhadas. Por fim, as considerações finais.
Histórico da Licenciatura em Educação do Campo da Universidade de Brasília

A Licenciatura em Educação do Campo da Universidade de Brasília iniciou em 2007, em parceria com o Instituto Técnico de Capacitação e Pesquisa da Reforma Agrária (ITERRA). A primeira turma da LEdoC/UnB aconteceu antes do lançamento do Edital $n^{\circ}$ 9, de 23 de abril de 2009, do Ministério da Educação, sobre as Licenciaturas em Educação do Campo. A segunda turma iniciou em 2008, também em parceria com o ITERRA. Em 2009, iniciou a terceira turma com estudantes de vários estados, tais como: Minas Gerais, Mato Grosso do Sul, Goiás e Distrito Federal. De acordo com o PPP-Projeto Político Pedagógico do curso (2009, p. 3), a Licenciatura em Educação do Campo da UnB "tem como objeto a escola de Educação Básica do Campo, com ênfase na construção da organização escolar e do trabalho pedagógico para os anos finais do Ensino Fundamental e do Ensino Médio”.

Pretende formar e habilitar profissionais na educação fundamental e média, que ainda não possuam a titulação mínima exigida pela legislação educacional em vigor, quer estejam em exercício das funções docentes, ou atuando em outras atividades educativas não escolares junto às populações do campo. [...] preparar educadores para uma atuação profissional que vai além da docência, dando conta da gestão dos processos educativos que acontecem na escola e no seu entorno (PPP, 2009, p. 3).

A organização das turmas, segundo Barbosa (2012), se 4eu pautada nas demandas da comunidade. A seleção para o ingresso do aluno levou em conta um vestibular diferenciado, den- tro de uma política afirmativa que contemplou os trabalhadores e trabalhadoras do campo.

Sobre o processo seletivo para a Licenciatura em Educação do Campo da Universidade de Brasília, Barbosa (2012) destaca que as inscrições foram gratuitas para atender à demanda da política afirmativa em questão, além da preocupação de garantir que as vagas fossem de fato acessadas por aqueles que realmente moram e trabalham no campo. A autora afirma que a turma constituída em 2007 foi formada por alunos oriundos das regiões Sul e Sudeste, em acordo previamente discutido com o Ministério da Educação, tendo em vista que a primeira turma se tratava um projeto piloto que depois seria avaliado e estendido para as demais instituições públicas de nível superior.

A segunda turma, com ingresso em 2008, foi organizada com vestibular para alunos do Centro-Oeste, conforme citado; para isso, as provas foram realizadas em Brasília e em Mato Grosso do Sul. Essa foi a primeira vez que a Licenciatura contou com alunos quilombolas, oriundos do município de Cavalcante - Goiás. Em 2009 foi realizado vestibular para a terceira turma. Para este grupo, foi questionada a função da declaração assinada pelos movimentos sociais, pois apenas essa declaração não garantia a entrada de pessoas que realmente viviam e trabalhavam no campo. Portanto, foi solicitada uma autodeclaração do estudante, atestando que era morador do campo.

Em 2010 não houve vestibular. Foi apresentado um pedido ao Conselho de Ensino, Pesquisa e Extensão - CEPE/UnB, para realizar vestibular apenas em 2011, para que pudesse melhor atender às demandas dos alunos que já estavam matriculados, refe- 
comCiência

Uma revista multidisciplinar
Formação docente na licenciatura em educação do campo da Universidade de Brasília Campus Planaltina rente a alojamento e demais questões pedagógicas. Nos anos que se seguiram, de 2011 a 2018, o vestibular foi realizado anualmente, com a oferta de 60 vagas para cada habilitação. Atualmente a LEdoC/UnB está em sua décima primeira turma.

Em 2017, a Licenciatura completou dez anos e foi comemorada com a presença de vários ex-alunos da LEdoC/UnB e de outros estados do Brasil, acampados nas dependências do Campus. As comemorações ocorreram dentro da semana universitária realizada pela Universidade de Brasília que teve, neste espaço de tempo, palestras, oficinas, seminários, mesas e rodas de conversa, apresentações culturais, místicas, exposição de produtos da agricultura familiar, lançamentos de livros, dentre outras atividades.

\section{A organização curricular e a forma- ção por área do conhecimento}

A organização curricular foi proposta de modo que pudesse dialogar com a realidade dos sujeitos do campo e sua diversidade. Segundo o PPP do curso (2009), o currículo está organizado em três grandes núcleos, sendo: estudos específicos, estudos básicos e atividades integradoras.

O núcleo de estudos específicos se desdobra em três eixos: formação por área do conhecimento, gestão de processos educativos escolares e a gestão de processos educativos comunitários. O núcleo de atividades básicas se constitui de cinco áreas: teoria e prática pedagógica, economia política, filosofia, política educacional e leitura, interpretação e produção de textos. $\mathrm{O}$ núcleo de atividades integradoras se divide em: pesquisas, práticas pedagógicas, estágios, seminários integradores e outras atividades científicoculturais.
As atividades referentes aos núcleos apresentados não acontecem de modo estanque, elas se dão de forma dialética e são distribuídas ao longo dos semestres. Algumas dessas atividades, como teoria e prática pedagógica e os seminários integradores acontecem em todos os semestres. Os seminários integradores são atividades formativas para os alunos e os professores formadores que atuam no curso. São momentos de problematização da realidade em que estão inseridos os estudantes, avaliação do curso e planejamento das atividades formadoras.

As atividades de gestão de processos educativos escolares e comunitários referem-se às atividades realizadas no tempo comunidade. Elas são ações nas quais os estudantes são colocados em contato direto com a escola de Educação Básica e com a comunidade. Na LEdoC essas ações são chamadas de Inserção Orientada na Escola (IOE) e Inserção Orientada na Comunidade (IOC).

A Inserção Orientada na Escola e na Comunidade constitui-se de atividades realizadas durante o Tempo Comunidade (TC). São atividades planejadas no Tempo Universidade, com a orientação e acompanhamento dos professores formadores. Podem ser um diagnóstico da escola e seu entorno, projetos de intervenção no campo, articulados com as diferentes disciplinas do currículo do curso, podem ser palestras, participação em alguma ação realizada pelos movimentos sociais e sindicais da região, grupos de jovens, grupos de teatro, grupos culturais em geral, ou pode ser uma ação específica tipo um mutirão para limpeza e preservação de uma nascente, criação de grupos de mulheres, etc.

As atividades de IOE e IOC têm a função de inverter a lógica conteudista da formação e superação da hegemonia verbalista, conforme ressalta Santos (2012). São atividades que possibilitam o protagonismo dos estudantes. O movimento constituído é profundamente marcado pela dialética, na qual a lógica de organização do trabalho pedagógico sofre uma inversão em relação ao processo hegemônico. Enquanto a lógica de produção do conhecimento predominante parte da teoria para compreender a realidade, na LEdoC, existe a intenção de que a realidade, as vivências, as tramas e contradições da escola e da comunidade apontem os caminhos teóricos dentro do contexto da aprendizagem (SANTOS, 2012, p. 101).

A distribuição dos componentes curriculares na LEdoC/UnB possui uma carga horária de 3.535 horas aula e 235 créditos distribuídos em 8 semestres, os quais se pautam nas matrizes formadoras da Educação do Campo e dos princípios fundantes da proposta. Molina e Sá (2011) destacam seis princípios fundantes. $\mathrm{O}$ primeiro refere-se aos saberes necessários à prática docente que deverão ser oportunizados aos acadêmicos a partir da relação entre a escola e a vida.

O segundo princípio trata de buscar a vinculação entre "os processos sociais vividos, em um sentido de transformação social, articulando-se criticamente aos modos de produção do conhecimento e da vida presentes na experiência social" (MOLINA; SÁ, 2011 , p. 40). Isso significa que a organização do trabalho pedagógico na Licenciatura em Educação do Campo da Universidade de Brasília considera que a produção do conhecimento se faz em diferentes instâncias, para além da universidade, de modo a legitimar a produção de saberes, advindos das práticas e das relações sociais e de produção dos sujeitos do campo.

Rev. ComCiência - dez. 2018, vol. 3, no. 3, p. 57-67 / doi: 10.36112/issn2595-1890.v3i1.p57-67 
comCiência

Uma revista multidisciplinar
Formação docente na licenciatura em educação do campo da

Universidade de Brasília Campus Planaltina
O terceiro princípio se refere à compreensão do curso como formação humana e da escola unitária, ou seja, parte da ideia de que os sujeitos devem acessar os conhecimentos em sua integralidade superando a escola dualista em que a classe trabalhadora é excluída do acesso aos conteúdos de formação geral, da cultura, das artes, da literatura, da ciência etc. Entendendo que a formação humana, na perspectiva de Gramsci (2001), implica o conhecimento, tanto da técnica quanto da ciência, ou seja, o sujeito precisa saber fazer e compreender como se faz e porque se faz.

O quarto princípio trata da transformação social da escola de Educação Básica. Para isso, as autoras destacam que é preciso compreender com clareza quais são os valores e as relações sociais que poderão dar sentido contra-hegemônico à forma de escola pública atual.

O quinto princípio diz respeito às dimensões chaves que fundamentam a organização curricular e pedagógica, sendo:

Uma matriz educativa multidimensional, que permita ampliar a função social da escola; o diálogo com as agências formadoras do meio; o trabalho e o desenvolvimento humano integral como base da aprendizagem, superando a ênfase estritamente cognitiva da escola capitalista (MOLINA; SÁ, 2011, p. 41).

Dentro desse princípio situa-se a organização do trabalho, a partir da proposta do Complexo de Estudo do pedagogo socialista Pistrak, que discute os fundamentos da escola do trabalho, entendendo o trabalho como princípio educativo. Ainda associada à discussão da escola do trabalho, baseada em Pistrak (2000), a LEdoC/UnB traz, em sua proposta, a ideia da autoorganização dos estudantes como es- tratégia de construção da cultura da coletividade.

O sexto princípio é a formação por área, cujo objetivo é superar o processo de fragmentação do conhecimento ao instituir a docência multidisciplinar, conforme abordaremos no item a seguir.

\section{A formação por área do conheci- mento na formação docente multi- disciplinar}

A formação de professores para aturarem nas escolas de Educação Básica no campo, desenvolvida pela LedoC/UnB, é organizada por alternância, na qual os estudantes vivenciam a formação a partir do Tempo Universidade e do Tempo Comunidade. $\mathrm{O}$ Tempo Universidade é desenvolvido no Campus da UnB de Planaltina. Neste tempo, os estudantes passam cerca de trinta a trinta e cinco dias na universidade com aulas presenciais. $\mathrm{O}$ Tempo Comunidade é realizado na comunidade rural de origem dos estudantes, dedicado a estudo e aprofundamento das teorias e da vivência.

É no Tempo Comunidade que os estudantes desenvolvem as atividades de Inserção Orientada na Escola e na Comunidade. Para as atividades de inserção na escola, são planejadas atividades nas quais colocam o estudante universitário em contato direto com a escola, desde o primeiro semestre do curso.

A organização da formação se dá por área do conhecimento. Essa formação, segundo Caldart (2011), objetiva a preparação do docente multidisciplinar, bem como a crítica e superação da fragmentação do conhecimento e o desenvolvimento do trabalho coletivo docente. Para essa autora, a formação dos educadores do campo, deve ser ancorada em um projeto de transformação da forma escolar atual, visando contribuir especialmente no pensar de dois de seus aspectos fundamentais, que são: a alteração lógica de constituição de plano de estudos, visando a desfragmentação curricular pela construção de um vínculo mais orgânico entre o estudo que se faz dentro da escola e as questões da vida dos seus sujeitos concretos; e a reorganização do trabalho docente, objetivando superar a cultura do trabalho individual e isolado dos professores (CALDART, 2011, p. 97).

A autora aponta a questão da formação por área ter como foco a transformação da escola de Educação Básica em seu conteúdo e forma; isso significa que a formação se organiza a partir das necessidades da escola, futuro espaço no qual o acadêmico atuará como profissional da educação. A segunda questão apontada é a alteração no planejamento e a intencionalidade da formação a ser desenvolvida na Educação Básica.

A terceira questão, na qual nos alongaremos um pouco mais, por ser um tema que tem merecido maior atenção no cenário educacional brasileiro, é a superação da fragmentação do conhecimento a partir da concepção disciplinar do currículo. Essa proposta visa construir outra lógica de organização curricular, ao conceber o conhecimento a partir da totalidade das construções humanas. Desta forma, compreende que o conhecimento não é estanque e linear, ele é dinâmico e dialético.

A questão apresentada referese ao vínculo entre os conteúdos escolares e as questões da vida. Neste sentido, é necessário refletir sobre: que conteúdo e que aula didática podem contribuir para o processo de humanização dos educandos? Tal questão traz à tona a historicidade, a politização $\mathrm{e}$ os elementos culturais que são impor- 
comCiência

Uma revista multidisciplinar
Formação docente na licenciatura em educação do campo da Universidade de Brasília Campus Planaltina tantes na constituição dos processos educativos dos estudantes. Outro aspecto importante diz respeito à superação do trabalho docente individualizado. Para superar o isolamento do trabalho do professor, a formação por área do conhecimento demanda um trabalho interdisciplinar. A interdisciplinaridade na formação requer um trabalho coletivo dos professores para discutir os diferentes conteúdos e arcabouço teórico que dará conta de abarcar a área do conhecimento, na perspectiva de construir uma compreensão da área, e não da disciplina.

Para tanto, a formação por área do conhecimento, segundo Caldart (2011, p. 101), precisa superar quatro desafios. O primeiro, a compreensão da profissionalização a ser desenvolvida pelas Licenciaturas em Educação do Campo, por área de conhecimento, enquanto na Educação Básica ainda é disciplina. Então, por que formar por área do conhecimento? Nesse sentido, precisamos lembrar que, segundo o Decreto 7.352 de 2010 da Presidência da República, o professor formado pelas Licenciaturas em Educação do Campo deve ser aquele que está preparado para fazer gestão dos processos educativos escolares e comunitários; portanto, faz parte da função social dessas licenciaturas ajudar os professores e a comunidade das escolas de Educação Básica a fortalecer a escola do campo e a comunidade.

O segundo desafio das licenciaturas é "[...] fazer do campo um objeto central de estudo sistemático e rigoroso do curso integrando ao perfil de formação desses educadores o esforço teórico de compreensão e análise da especificidade do campo" (CALDART, 2011, p. 102). Nesse objetivo está presente a necessária relação entre educação e trabalho a partir da análise, entre outros fatores, dos processos produtivos e de trabalho vinculados aos movimentos sociais, à agricultura etc. Dessa forma, a licenciatura contribuirá para a produção de conhecimento socialmente útil aos sujeitos que vivem e trabalham no campo.

O terceiro desafio é propor a organização do curso de formação de professores, a partir de uma visão mais ampla da educação, no sentido de contribuir para a formação do perfil de professor que possa responder às demandas da Educação do Campo, de modo que ela também possa compreender a educação para além da escola, entendendo que os processos formativos podem se materializar em vários espaços e em tempos diferenciados. "Educação não é igual a escola e escola não é igual a ensino ou a instrução cognitiva. Mas há uma especificidade do processo educativo escolar (e de docência) e se preparar para atuação (alargada) nele é um dos principais objetivos desta Licenciatura" (CALDART, 2011, p. 103).

O quarto desafio diz respeito ao fato de que é necessário que as licenciaturas em Educação do Campo desenvolvam "estratégias pedagógicas" a partir da práxis do curso, mediada pela intrínseca relação entre teoria e prática. Nesse sentido, a teoria e a prática entendidas como práxis significam que a ação pedagógica do curso, na formação dos futuros professores, deve objetivar a transformação da realidade e do sujeito em formação, de modo que este estudante (acadêmico) possa desencadear processos formativos na escola e em sua comunidade (CALDART, 2011). Além dos desafios, a autora, destaca algumas tensões que podem surgir em torno do debate da formação por área do conhecimento e da docência multidisciplinar. A primeira tensão que a autora aponta é tirar o foco da formação do educador da escola, pois a tradição de formação de professores no Brasil tem centrado na escola

Uma segunda tensão, tratada por Caldart (2011), refere-se à necessidade de formar professores que compreendam a Educação Básica como uma totalidade, superando a cisão entre ensino fundamental e médio, ou seja, é preciso entender que o percurso formativo que o estudante deve fazer na Educação Básica é um contínuo, que deve prepará-lo para a vida, e que ensino fundamental e médio fazem parte de um todo que prepara o sujeito para se colocar na sociedade, compreendendo a si mesmo e o mundo que o cerca.

Para tanto, a formação por área na docência multidisciplinar na Licenciatura em Educação do Campo inaugura um novo olhar sobre a formação de professores, por compreender a relevância deste profissional na definição dos rumos da educação pública brasileira e na luta por uma escola pública de qualidade.

\section{A Pedagogia da Alternância na for- mação de professores}

Antes de iniciarmos a reflexão sobre a Pedagogia da Alternância na formação de professores, é oportuno contextualizarmos historicamente a gênese dessa Pedagogia, de modo que possamos compreender a importância desta proposta na Educação do Campo e nas Licenciaturas em Educação do Campo.

A alternância, segundo Queiroz (2004), foi gestada na França no ano de 1935, em Lot-et-Garone, situada na região sudeste. Uma das preciosidades dessa pedagogia é que ela foi pensada por agricultores, com objetivo de melhor responder às demandas 


\section{ComCiência}

Uma revista multidisciplinar
Formação docente na licenciatura em educação do campo da Universidade de Brasília Campus Planaltina daquele tempo, no tocante à educação para pessoas que viviam na zona rural.

$\mathrm{Na}$ década de 30, a França passava por fortes momentos de crise. Surge a necessidade de reestruturar a economia, a política e o social. As políticas públicas pensadas voltavam para os problemas urbanos; então os agricultores se reúnem em um movimento chamado Sillon e cria em seu processo organizacional o SCIR- Secretariado Central de Iniciativa Rural. (QUEIROZ, 2004).

O início da Pedagogia da Alternância se dá em meio a um "processo de organização e de reflexão", conforme ressalta Chartier (1986, p. 43 apud QUEIROZ, 2004, p. 62). Desse modo, o movimento do Sillon fez uma referência significativa de educação do contexto francês da década de 1930, tanto que, sob a influência desse movimento, foi criada a primeira escola fundada sobre os princípios da Pedagogia da Alternância, conhecida como Casa Familiar Rural ou Maison Familiale Rurale de Lauzun, no ano de 1937, em Sérignac-Perboudou.

A primeira escola de alternância teve como primeiro professor o padre Abbé Granereau com um grupo de jovens rapazes. A experiência deu certo e se ampliou para o atendimento de mulheres. Segundo Santos (2012, p. 53), “entre 1940 e 1941, é criada a primeira Casa Familiar para mulheres em Lauzan com uma turma de 35 estudantes". Os protagonistas da primeira experiência com a Pedagogia da Alternância foram:

Jean Peyrat, agricultor e membro do SCIR; M. Callewaert, agricultor e membro do sindicato agrícola; Edouard Clavier, agricultor; e o padre Abbé Granereau, que era agricultor, membro do Sillon e do SCIR. Segundo relatos, Yves, filho de Jean Peyrat, não manifestava vontade de frequentar a escola con- vencional da época, pois não queria se afastar do ofício de agricultor. Preocupado com a situação, o pai (Jean Peyrat) leva a problemática ao padre Granereau, e ele, aos demais agricultores do SCIR. Como resultado dessas reflexões, definiuse que os jovens da região de Lotet-Garonne receberiam uma formação técnica, geral, humana e cristã. Como princípio básico, tal formação seria em alternância, e a responsabilidade dela seria das famílias [...] (SANTOS, 2012, p. 52-53 apud QUEIROZ, 2004, p. 66).

O sucesso da experiência francesa foi tal que se espalhou por vários países. No Brasil, a Pedagogia da Alternância chegou em 1969, pelo Estado do Espírito Santo, por intermédio do Padre missionário italiano Humberto Pietro Grande que já conhecia essa Pedagogia pela experiência italiana. No Brasil, essas escolas ficaram conhecidas como Escolas Famílias Agrícolas (EFAs). Além das EFAs temos no Brasil as Casas Familiares Rurais (CFR) com incidência nos estados do Rio Grande do Sul, Paraná e Santa Catarina. As EFAs hoje estão presentes nos estados da Bahia, Maranhão, Sergipe, Rondônia, Minas Gerais, Piauí, Pará, Amapá, Goiás, Tocantins, Rio de Janeiro, Mato Grosso do Sul, entre outros. Tanto as EFAs quanto as CFRs trabalham com educação básica de nível fundamental e médio e educação profissional de nível médio.

A entrada da Pedagogia da Alternância no nível superior e na formação de professores se deu a partir dos movimentos sociais e sindicais do campo, a partir das Licenciaturas em Educação do Campo regidas pelo Programa Nacional de Educação do Campo (PRONACAMPO), cujo objetivo é formar professores para atuarem nas escolas das comunidades rurais, a partir da gestão de processos educativos escolares e comunitários, por meio da alternância pedagógica, conforme citado anteriormente. Gimonet (2004) chama atenção para o tipo de alternância a ser desenvolvida. A instituição deve fazer a opção pela alternância integrativa, que é aquela que integra, de modo orgânico, o tempo escola ou universidade e o tempo comunidade, conforme destaca:

Esta não se limita a uma sucessão dos tempos de formação teórica e prática, mas realiza uma estreita conexão e interação entre os dois, além de um trabalho reflexivo sobre a experiência. Este tipo de alternância privilegia o projeto pessoal e coloca o formando como ator envolvido em seu meio (GIMONET, 2007, p. 120).

A alternância apresenta quatro finalidades básicas citadas por Gimonet (2004), sendo: orientação, adaptação, qualidade e identidade profissional e formação geral. Quanto, à orientação o autor destaca que o estudante é posto diante das diferentes experiências do meio social e profissional, de modo que possa escolher sua profissão. A adaptação ao trabalho objetiva oportunizar aos estudantes um instrumento pelo qual possa estabelecer a relação entre a teoria e a prática, como meio para a construção de qualificação técnica profissional.

A terceira finalidade, a qualificação e identidade profissional, refere-se ao exercício de uma profissão. Para isso, o contato com a área é importante para "[...] a construção de uma identidade profissional duradoura"; a quarta finalidade, a formação geral, objetiva a superação da separação entre trabalho manual e intelectual de modo a formar o sujeito na perspectiva integral, em diferentes dimensões (GIMONET, 2004, p. 51).

Portanto, na formação de professores, a alternância, os tempos for- 
comCiência

Uma revista multidisciplinar
Formação docente na licenciatura em educação do campo da Universidade de Brasília Campus Planaltina mativos se constituem em tempo de aprendizagem e produção de conhecimentos. Durante o tempo comunidade, os estudantes da Licenciatura realizam as atividades de inserção que na Universidade de Brasília são chamados de Inserção Orientada na Escola (IOE) e Inserção Orientada na Comunidade (IOC).

A IOE se dá a partir da inserção do estudante no contexto da escola de Educação Básica do campo, através de diversas atividades. A primeira atividade se dá a partir da observação e da realização do diagnóstico ou inventário de estudo sobre a escola e a comunidade em seu entorno.

A IOC se dá pela inserção do aluno nas atividades e na vida coletiva da comunidade. Para isso, é importante identificar quais são as instituições que permeiam o espaço da comunidade rural da qual o acadêmico, futuro docente, faz parte. Também, é importante diagnosticar as tensões e contradições que coexistem no espaço comunitário rural, por entender que elas influenciam na organização da escola de uma dada comunidade.

Para tanto, as atividades de Inserção Orientada na Escola e na Comunidade são instrumentos (não únicos), pelos quais os estudantes poderão fazer a gestão de processos educativos na escola, bem como na comunidade. A ideia é que o estudante universitário entre em contato com a escola desde o primeiro semestre, tendo em vista que o espaço escolar é, em grande medida, o espaço no qual o estudante poderá construir sua identidade profissional.

\section{DISCUSSÃO DOS DADOS}

A discussão dos dados se deu a partir dos dados produzidos pelos questionários enviados aos professores da Licenciatura em Educação do Cam- po na Universidade de Brasília. A análise documental trouxe dados do Projeto Político Pedagógico (PPP) da LEdoC UnB. Entre os professores convidados a responderem ao questionário, apenas um enviou as respostas. Os dados foram analisados a partir de três categorias: organização curricular da LEdoC, organização pedagógica e relação com os movimentos sociais.

Iniciamos a discussão dos dados pela análise do PPP. Antes de prosseguirmos, é importante destacar que pautamos nossa análise no Projeto Político Pedagógico vigente e homologado pelo CEPE. Contudo, este documento está sendo reformulado pelo Colegiado de Professores da LEdoC e o novo documento ainda está em elaboração, com previsão para discussão no CEPE até o final do primeiro semestre de 2018.

Em relação à organização curricular da LEdoC, seu PPP (2009) busca:

Organizar os componentes curriculares em quatro áreas do conhecimento: Linguagens; Ciências $\mathrm{Hu}$ manas e Sociais; Ciências da Natureza e Matemática; Ciências Agrárias; de modo que os estudanteseducadores possam vivenciar, na prática de sua formação, a lógica do trabalho pedagógico para o qual estão sendo preparados. Organizar metodologicamente o currículo por alternância entre Tempo/Espaço Escola-Curso e Tempo/Espaço Comunidade-Escola do Campo, de modo a permitir a necessária dialética entre educação e experiência, oferecendo preparação específica para o trabalho pedagógico com as famílias e ou grupos sociais de origem dos estudantes, para liderança de equipes e para a implementação (técnica e organizativa) de projetos de desenvolvimento comunitário sustentável (PPP, 2009, p. 11-12).

Para levantar dados acerca da organização curricular do curso foi feita a seguinte pergunta: "Como é organizado o currículo do curso de
Licenciatura em Educação do Campo da Universidade de Brasília?”.

Ao se organizar por área do conhecimento, o curso precisa dialogar com as questões ligadas à inter, multi e transdisciplinaridade, visando superar a fragmentação do conhecimento. Sobre esse aspecto, o PPP destaca que "têm assumido formas diferenciadas, como, em primeiro lugar a multidisciplinaridade, ou seja, o estudo de um objeto de uma mesma e única disciplina por várias disciplinas diferentes" (PPP, 2009, p. 12).

Entre os objetivos gerais da formação, o PPP (2009, p.16) aponta "desenvolver estratégias de formação para a docência multidisciplinar em uma organização curricular por áreas do conhecimento nas escolas do campo". Consideramos que esse objetivo está em consonância com a proposta de formação por área do conhecimento. Os demais objetivos tratam de questões mais gerais sobre a formação de professores, que é comum aos cursos dessa natureza e não apenas ao curso de Licenciatura em Educação do Campo, por essa razão não nos deteremos na sua discussão.

Entre os objetivos específicos, enfocaremos os objetivos B, C, D, e E. Quanto ao objetivo B, visa formar professores para as áreas de Ciências da Natureza e Matemática e linguagens, ambos na perspectiva da formação por área do conhecimento. O objetivo $\mathrm{C}$ fala da formação de professores que possam, em sua realidade, fazer a gestão de processos educativos tanto na escola, quanto na comunidade.

Uma questão interessante, a ser destacada no objetivo $\mathrm{C}$, é que a formação do professor da LEdoC pretende preparar o futuro professor para aprender a identificar as potencialidades e fragilidades que permeiam sua realidade, de modo que esse sujeito 
comCiência

Uma revista multidisciplinar
Formação docente na licenciatura em educação do campo da

Universidade de Brasília Campus Planaltina possa contribuir para o desenvolvimento sustentável do campo. Podemos nos perguntar por que o professor precisa se ocupar com questões ligadas ao desenvolvimento do meio rural? Para a Educação do Campo, a escola da comunidade camponesa é percebida como uma ferramenta de desenvolvimento das pessoas e da comunidade; portanto, ao professor do campo, apresentam-se desafios, tais como a manutenção do campesinato, ou seja, da vida no campo significa também a manutenção das escolas nas comunidades camponesas, as escolas do campo são ferramentas de fortalecimento de seus sujeitos.

Quanto ao objetivo D, bastante inusitado, refere-se à preparação dos estudantes para implementar escolas públicas de Educação Básica em suas comunidades. É pouco comum encontrarmos um objetivo dessa natureza no PPP dos cursos de formação de professores. Percebemos que é um objetivo bastante ousado e desafiador, porém muito pertinente no contexto da população que vive no e do campo, tendo em vista que a demanda por escolas de Educação Básica no campo é muito intensa. Além disso, a política de fechamento das escolas do campo para diminuir os custos significa uma ameaça ao campesinato.

No que se refere ao objetivo E, vale destacar que está em consonância com a proposta de formação por área do conhecimento, ao referir-se à necessidade de "capacitar professores na perspectiva transdisciplinar". A ideia em oferecer aos futuros docentes a compreensão da formação pretendida pela Educação do Campo é maior que a própria escola, pois concebe a formação a partir da transdisciplinaridade inter-relacionada à compreensão de formação como formação humana, inaugura um novo jeito de fazer para os cursos de formação de professores.

Quanto à docência multidisciplinar, é oportunizada aos estudantes a habilitação em uma das áreas já citadas anteriormente. Não aparece, no perfil do egresso, uma descrição mais detalhada sobre a compreensão da docência multidisciplinar e sua função. Sobre a gestão de processos educativos nas comunidades, aparece de modo mais claro no perfil do egresso, enfatizando a importância desse sujeito formado na LEdoC manter um vínculo forte com a comunidade e os movimentos sociais e sindicais do campo, entendendo que a formação desenvolvida na licenciatura deve alcançar também a comunidade.

Sobre os sete princípios orientadores, apresentamos a sua relação com as categorias de análise dessa pesquisa, já mencionadas no início do tópico sobre a análise dos dados.

No que se refere à organização curricular, o primeiro princípio apresentado pelo PPP (2009) fala sobre a organização curricular por área do conhecimento. No tangente à categoria de análise, organização pedagógica, este princípio pauta-se no trabalho pedagógico interdisciplinar. Tanto a formação por área do conhecimento quanto a interdisciplinaridade na formação têm, como finalidade, oportunizar aos estudantes a vivência da relação teoria e prática, ou seja, os estudantes vão compreender o método, formação por área e interdisciplinaridade, vivenciando-os na formação acadêmica.

Em relação à organização pedagógica, o segundo princípio trata da "relação não-hierárquica e transdisciplinar entre diferentes tipos e modos de produção de conhecimento". Isso evidencia a preocupação com a construção de novas epistemologias e o professor que comprometimento com a produção de conhecimento voltado para os trabalhadores e trabalhadoras do campo.

O terceiro princípio demonstra a preocupação da Licenciatura em Educação do Campo da Universidade de Brasília com a formação de um profissional que seja capaz de compreender os processos contraditórios, as tensões, os problemas e potencialidades de sua realidade, e construa caminhos para superá-los, a partir da pesquisa. Nesse princípio, podemos perceber a categoria organização pedagógica, que se inscreve nessa pesquisa.

$\mathrm{O}$ quarto princípio trata sobre "processos, metodologias e postura docente que permitam a necessária dialética entre educação e experiência" (PPP, 2009, p. 20). Está claro que a licenciatura apresenta uma organização pedagógica que se pauta na trajetória do estudante em formação, ao valorizar a experiência de vida do discente. Outra categoria de análise presente neste princípio é a relação com os movimentos sociais, ao valorizar as vivências socioculturais dos estudantes.

O quinto princípio refere-se à compreensão da docência como formação humana. Em relação às categorias de análise, compreendemos que se inscreve na categoria organização pedagógica, pois define uma concepção de formação de professores.

O sexto princípio "visão de totalidade da Educação Básica" (PPP, 2009, p. 20) apresenta uma compreensão da Educação Básica em uma perspectiva mais abrangente. Ele traz um caráter inovador ao desfragmentar a Educação Básica, deixando de concebê-la como fases distintas e estanques. A formação do docente na LEdoC/UnB compreende que o professor 


\section{ComCiência}

Uma revista multidisciplinar
Formação docente na licenciatura em educação do campo da Universidade de Brasília Campus Planaltina precisa entender essa modalidade educativa como contínua.

O sétimo e último princípio "abordagem da escola nas suas relações internas e com o contexto onde ela se insere" (PPP, 2009, p. 20) é bastante interessante ao ampliar a dimensão da escola para além dela mesma. Esta compreensão na formação dos futuros educadores é muito inovadora e atual. Entendemos que a escola é uma representação da sociedade e, portanto, as questões sociais, políticas e culturais que permeiam a comunidade também aparecerão de forma latente na instituição escolar. Dessa forma, entendemos que esse princípio dialoga com a categoria de análise, a organização curricular e pedagógica, uma vez que esse tipo de compreensão precisa estar imersa em toda estrutura curricular e pedagógica do curso, superando inclusive a ideia de que esse tipo de discussão seja feito por um dos componentes curriculares, ao contrário disto, esta compreensão perpassa transversalmente a proposta do curso de Licenciatura em Educação do Campo.

Após a análise documental, apresentamos a análise dos dados obtidos através da aplicação do questionário. Este instrumento foi respondido por uma das professoras do curso. Os demais professores convidados a participarem da pesquisa não retornaram o questionário com as respostas.

Em relação à primeira pergunta do questionário "Como é organizado o currículo do curso de Licenciatura em Educação do Campo da Universidade de Brasília?"

Organização curricular do curso é feita por áreas de conhecimento em que se busca interdisciplinar essas áreas, em etapas presenciais (equivalentes a semestres de cursos regulares), em regime de alternância entre Tempo Universidade e Tempo Comunidade. A matriz curricular proposta desenvolve uma estratégia multidisciplinar de trabalho docente, organizando os componentes curriculares a partir de três áreas do conhecimento: Linguagens, contemplando Artes visuais, Teatro e Literatura; Ciências Humanas e Sociais; Ciências da Natureza e Matemática. Os Tempos e Espaços formativos do Curso se desenvolvem de acordo com a carga horária curricular de cada etapa e da forma como estão organizados os componentes curriculares e sua metodologia. O currículo está organizado em três núcleos: Núcleos de Estudos Básicos (NEB), Núcleo de Estudos Específicos (NEE) e Núcleo das Atividades Integradoras (NAI), com a seguinte composição de carga horária: Núcleo de Estudos Básicos $=795$ h/a, Núcleo de Estudos Específicos $=1410 \mathrm{~h} / \mathrm{a}$ e Núcleo de Atividades Integradoras $=1320 \mathrm{~h} / \mathrm{a}$ (RESPONDENTE A, 2018).

A resposta dada apresenta compreensão sobre a organização curricular do curso, que é pautada na formação por área do conhecimento e na pedagogia da alternância. Evidencia que o professor tem conhecimento das principais questões apresentadas no Projeto Político Pedagógico (PPP) do curso. Essa percepção é de fundamental importância para a materialidade de uma proposta como esta. Sabemos que as definições de PPP, ou de uma lei, só se concretizam se puderem se materializar nas práticas dos sujeitos. Deste modo, a respondente demonstra que conhece a proposta e que procura incorporá-la em sua prática docente.

Em relação à segunda pergunta do questionário "Como a Pedagogia da Alternância contribui para a formação do professor que atuará nas escolas de Educação Básica do Campo”, tivemos a seguinte resposta:

A proposta educativa e formativa do curso em regime de alternância ocorre em articulação da teoria com a prática, que permite aos estudantes melhor compreensão de sua realidade para que possa nela interferir com vistas à transformação social. Nesse sentido, a formação pressupõe um processo de construção da autonomia, em busca da emancipação humana. A Licenciatura em Educação do Campo tem a intenção de preparar educadores para uma atuação além da docência, dando conta dos processos de gestão escolar e comunitário. Nesse sentido, a alternância propõe e desenvolve processos participativos e coletivos estabelecendo relações democráticas entre escola e comunidade. A alternância possibilita o encontro de educadores e educandos na produção do conhecimento numa relação dialética e dialógica, fortalecimento os processos formativos, em que ensino e aprendizagem se constituem parte de um processo educativo e formativo [...]. (RESPONDENTE A, 2018).

A respondente A coloca em evidência a necessária relação entre teoria e prática no processo de formação dos professores, desenvolvido pela Licenciatura em Educação do Campo, assim como leva a entender que para o bom desenvolvimento desta formação é necessário o acompanhamento das atividades em comunidade, bem como o domínio do método desenvolvido.

No que se refere à terceira pergunta do questionário "Qual o papel dos movimentos sociais na proposta da Licenciatura em Educação do Campo", obtivemos a seguinte resposta:

Os movimentos sociais assumem relevante papel na medida em que dialogam com os diferentes saberes e com eles se articulam e podem ser explorados nos espaços escolares e comunitários. Isso significa dizer que há uma dinâmica construída coletivamente que é constituinte do processo formativo [...]. Outro aspecto importante é a influência dos movimentos sociais na formulação de políticas públicas, o que ocorre 
comCiência

Uma revista multidisciplinar
Formação docente na licenciatura em educação do campo da

Universidade de Brasília Campus Planaltina por meio das articulações locais entre os Movimentos Sociais, Instituições de Ensino Superior (IES) e esferas governamentais (RESPONDENTE A, 2018)

Fica evidente que a vinculação com os movimentos sociais é imprescindível para o curso de Licenciatura em Educação do Campo, pois eles "assumem relevante papel na medida em que dialogam com os diferentes saberes e com eles se articulam e podem ser explorados nos espaços escolares e comunitários". Além disso, a participante da pesquisa destaca que os movimentos são importantes para a luta e proposição de políticas públicas relevantes para os sujeitos do campo.

Em relação aos movimentos sociais, a pesquisa abalizou que essa compreensão está dada para os professores, assim com aparece nas pesquisas e publicações da área, inclusive publicações feitas por professores da LEdoC/UnB, porém pouco aparece descrito no Projeto Político Pedagógico do curso.

\section{CONSIDERAÇÕES FINAIS}

A pesquisa procurou compreender o processo de formação de professores realizado pela Licenciatura em Educação do Campo da Universidade de Brasília a partir das categorias: organização pedagógica, organização curricular e relação com os movimentos sociais.

Em relação à organização pedagógica percebemos que o Projeto Político Pedagógico apresenta uma discussão não muito aprofundada da concepção teórica do que é formação por área. Essa discussão encontra-se bem aprofundada em muitas publicações de autoria de professores do curso como, por exemplo, as professoras doutoras Mônica Castagna Molina e
Laís Mourão Sá, em diversas publicações desde livros a artigos, e pela representante do movimento social Roseli Caldart.

Em relação à organização curricular, o Projeto Político Pedagógico é bem estruturado e bastante coerente com a proposta do curso. A organização dos núcleos de estudo é muito pertinente ao projeto formativo da Licenciatura em Educação do Campo.

No que se refere à relação entre a Licenciatura, os estudantes e os movimentos sociais, o Projeto Político Pedagógico traz poucos elementos que evidenciem como deve ser feita essa relação. Assim como não apresenta estratégias que indiquem quais ferramentas e em quais momentos essa relação poderá ser aprofundada durante o percurso formativo do futuro professor.

Em relação à escola de Educação Básica do Campo, o Projeto Político Pedagógico evidencia uma preocupação e intencionalidade pedagógica densa sobre a necessidade da Licenciatura se organizar a partir das necessidades das escolas das comunidades rurais, pautando a formação de professores nos problemas e potencialidades dessas comunidades, com vistas a construir, coletivamente, comunidade escolar, acadêmicos e professores da Licenciatura, respostas para as questões advindas do meio.

\section{REFERÊNCIAS}

\section{BARBOSA, Ana Isabel. A organiza-} ção do trabalho pedagógico na Licenciatura em Educação do Campo/UnB: do projeto às emergências e tramas do caminhar. Brasília, 2012.

Tese (Doutorado em Educação). Universidade de Brasília, Brasília, 2012.

\section{BRASIL. MINISTÉRIO DA EDU-}

CAÇÃ̃. Decreto $n^{\circ}$ 7352, de 5 de novembro de 2010. Dispõe sobre a política de educação do campo e o Programa Nacional de Educação na Reforma Agrária (PRONERA). Diário Oficial da União, Brasília, 5 nov. 2010, p. 1.

CALDART, Roseli Salete. Licenciatura do campo e projeto formativo: qual o lugar da docência por área? In:___. MOLINA, Mônica Castagna; SÁ, Laís Mourão (Org.). Licenciaturas em educação do campo. Belo Horizonte: Autêntica, 2011, p. 95-121.

CALDART, Roseli Salete. Licenciatura do campo e projeto formativo: qual o lugar da docência por área? In: CALDART, Roseli Salete et al. Caminhos para a transformação da escola: reflexões desde práticas da Licenciatura em Educação do Campo. São Paulo: Expressão Popular, 2011. p. $127-154$.

GIMONET, Jean-Claude. Praticar e compreender a pedagogia da alternância dos CEFFAs. Petrópolis: Vozes, 2007.

GIMONET, Jean-Claude. Método pedagógico ou novo sistema educativo? A experiência das Casas Familiares Rurais. In: Documentos pedagógicos. Brasília: UNEFAB, 2004, p. 21-31.

GRAMSCI, Antônio. Os intelectuais e a organização da cultura. 4. ed. Rio de Janeiro, 1982.

\section{GRAMSCI, Antônio. Cadernos do} cárcere. v. 2: os intelectuais, o princípio educativo, o jornalismo. Rio de Janeiro: Civilização Brasileira, 2001. 
MOLINA, Monica Castanga; SÁ, Laís Mourão. A licenciatura do campo da Universidade de Brasília: estratégias político-pedagógicas na formação de educadores do campo. In__. Molina, Monica Castanga; SÁ, Laís Mourão.Licenciaturas em educação do campo. Belo Horizonte: Autêntica, 2011, p. 35-61.

PISTRAK, Moisey Mikhaylovich. Fundamentos da escola do trabalho. São Paulo: Expressão Popular, 2000.

QUEIROZ, João Batista Pereira.

Construção das Escolas Famílias Agrícolas no Brasil: ensino médio e educação profissional. Brasília, 2004. Tese Doutorado em Educação. - Universidade de Brasília, Brasília, 2004.

SANTOS, Silvanete Pereira. A concepção de alternância da Licenciatura em Educação do Campo da Universidade de Brasília. Dissertação (Mestrado em Educação). Universidade de Brasília, 2012.

UNIVERSIDADE DE BRASÍLIA.

Projeto Político Pedagógico. Brasília:

LEdoC, 2009. (mimeo). 